\title{
Entre o pensar e o conhecer: um lugar para a diferença na formação de professores
}

Ida Mara Freire*

\section{Resumo}

$\mathrm{Na}$ tentativa de distinguir o pensar e o conhecer, o artigo apresenta um exercício de pensamento como possibilidade de atividade acadêmica na formaçáo de professores. O texto se pauta no exame crítico de algumas noçóes e conceitos que gravitam em torno da igualdade de direito à educação, a saber, estigma, diferença, direitos humanos, igualdade, e igualdade de oportunidades e ação afirmativa em diálogo com alguns filósofos contemporâneos, a saber, Hannah Arendt, Jacques Derrida, John Rawls e Peter Singer. Trilha-se um caminho que parte do juízo perceptivo e chega-se ao juízo ético, que atribui a igual consideração de interesses. Palavras-chave: Igualdade na educação. Professores - Formação. Igualdade na educação.

* Professora associada do Centro de Ciências da Educação (CED) da Universidade Federal de Santa Catarina (UFSC), pós-doutorado em Tópicos Especificos da Educação pela University of Nottingham, UK. 


\section{Introdução}

Cicatrizes, ausências, excessos: quem está diante de nós está sujeito ao nosso juízo perceptivo. "Como explicar a permanente hostilidade do homem em relação ao homem?”, indaga Tajfel (1982, p. 145) em seu clássico estudo sobre os aspectos cognitivos do preconceito. Suas investigaçóes traçam o imperceptível caminho de nossos processos de diferenciação, que vão de nosso juízo perceptivo aos estereótipos sociais:

Vivemos num mundo em que os processos de unificação e diversificação ocorrem rapidamente, ambos mais depressa do que nunca. Os grupos humanos em larga escala se comunicam, em certos aspectos, mais do que nunca uns com os outros, conhecem-se uns aos outros mais do que nunca, e têm-se tornado cada vez mais independentes. Ao mesmo tempo, verifica-se praticamente em todo mundo uma forte tendência no sentido de preservar ou alcançar a diversidade de características próprias e duma identidade específica. [...] A erosão, preservação e criação de diferenciaçôes tem sido, nos últimos anos, uma das características fundamentais de alguns dos mais graves conflitos sociais e industriais. [...] A diferenciação entre grupos sociais (e os conflitos sobre as diferenças, que são um caso particular daquela) não podem ser corretamente entendidos só em termos econômicos. São necessárias outras formas de análise para os compreender; elas não podem substituir as análises econômica e sociológica, mas devem-lhe servir de complemento. (TAJFEL,1982, v. 2b, p. 255; grifos do autor).

Para iniciarmos a nossa reflexão, tomamos como exemplo o estudo do conceito de estigma. As exigências que fazemos às pessoas estranhas são denominadas por Goffman (1988) como identidade social virtual. A categoria e os atributos que ele prova possuir são chamados de identidade social real. Deste modo, o estigma se refere à discrepância entre a identidade real e a virtual. Em outras palavras, o estigma é primeiramente uma característica com evidente descrédito que o indivíduo possui, que nos 
induz à não considerá-lo uma pessoa comum e total, e o reduzimos a uma pessoa "estragada", diminuída, incompleta. Podemos distinguir três tipos de estigma, um vinculado às deformidades corporais, outro relacionado à culpa de caráter individual, e ainda os estigmas tribais de raça, nação e religião.

As atitudes que se tem com uma pessoa estigmatizada e os atos que se empreendem em relação a ela são bem conhecidos socialmente. Parte-se da definição de que alguém com um estigma não seja completamente humano, e com isso posto, várias tipos de discriminação são feitas, e com isso as chances de esse alguém viver plenamente são reduzidas. Elabora-se também uma teoria do estigma, uma ideologia para explicar a sua inferioridade e dar conta do perigo que ela representa, justificando falsamente algumas vezes uma aversão baseada em outras diferenças. Utilizam-se termos específicos de estigma, no discurso diário como fonte de metáfora e representação de modo característico, sem refletir no seu significado original. Tende-se, de um lado, a inferir uma série de imperfeiçóes a partir de uma imperfeição original e, por outro, imputar ao interessado alguns atributos desejáveis, mas não desejados, frequentemente de aspecto sobrenatural, por exemplo, "sexto sentido" ou "dom". Por fim, pode-se "[...] perceber a sua resposta defensiva a tal situação como uma expressão direta de seu defeito, e, então, considerar os dois, defeito e resposta, apenas como retribuição de algo que ele, seus pais, ou sua tribo fizeram, e, consequentemente, uma justificativa da maneira com o tratamos" (GOFFMANN, 1988, p. 15).

Nas diversas tentativas de apreender, descrever, clarificar noçóes tais como: diferença, identidade, estigma, estereótipos, preconceito, igualdade e alteridade, percebemos que essas experiências de pensamento podem contribuir para o alargamento da nossa compreensão do mundo. Mas o leitor e a leitora podem indagar: quais seriam os argumentos para estudar as teorias acerca da diferença nos cursos de formação de professores? Um primeiro aspecto é que a escola tem sido apontada com um espaço mais de enfrentamento que de acolhimento da diferença (LUNARDI, 2005). Outro ponto importante: o professor pergunta sobre o que fazer com a diferença na escola (REGO, 1998). E um terceiro dado, a diferença é alvo de intolerância na sala de aula (ITANI, 1998). Neste sentido, supomos que a proposição de atividades acadêmicas que oportunizem o estudo da noção de diferença no curso de formação de professores possibilita a criação de ambiências para acolher a alteridade no espaço escolar. Diante dessa 
possibilidade, parece-nos válido explicitar como a Existenz só se torna clara através da razão e a razão só tem seu conteúdo através da Existenz (KARL JASPER apud ARENDT 1999, p. 78).

Nesta ação, almejamos aqui o que Edmund Husserl (1859-1938) propôs com sua Fenomenologia, a saber: uma exploração das fundaçóes conceituais requeridas em qualquer tipo de saber e cognição sem invocar ou atracar-se com as teorias ou posições filosóficas tradicionais. Distinta da Lógica pura e da Psicologia empírica, a Fenomenologia é concernente com a concretude dos atos de sentidos, sentido-intencionado, náo como ocorrência de fatos no mundo ou em termos de sentido ideal a eles articulado, mas o que eles têm de essencial e intencional, a priori estruturas. Além do mais, a clarificação da Lógica pura não pode simplesmente contar com os sentidos das palavras como são usadas ordinariamente, mas deve assegurar seus sentidos nas intuições concretas, ou seja, nós devemos voltar às coisas mesmas. A Fenomenologia fixa esses sentidos por voltar para a conexão entre atos que intencionam sentidos e aqueles atos que confirmam sentidos, sentidos-realização (MORAN, 2000, p. 91-94). Em seu estudo intitulado Sexta investigação, Husserl (1980) examina o retorno da intuição para a experiência lógica vivida que surge quando nós pensamos, ainda que nós não vejamos como isso se dá.

As questóes acerca do pensamento e do conhecimento devem ser examinadas com máximo rigor e sugerem "a volta às coisas mesmas", e para fazer isso necessitamos das reduçôes, ou seja, uma mudança de atitude, da natural para a filosófica, que pode ser de várias maneiras ou modelos, como por exemplo, uma atitude fenomenológica na busca de clarificação de conceitos como buscaremos fazer aqui, ao examinarmos a noção de igualdade. Reconhecemos, em concordância com o filósofo Jacques Derrida, que:

[...] há limites para o conceito. Em latim, assim como em francês ou alemão, o conceito (Begriff) nomeia o gesto de uma apreensão, é uma captura. A desconstrução passa por ser hiperconceitual, e decerto o é, fazendo um grande consumo dos conceitos que produz à medida que os herda - mas apenas até o ponto em que uma certa escritura pensante excede a apreensão ou o domínio conceitual. Ela tenta pensar o limite do conceito, chega a resistir à experiência desse 
excesso, deixa-se amorosamente exceder. É como um êxtase do conceito: goza-se dele transbordantemente. (DERRIDA; ROUDINESCO, 2004, p. 14).

A intenção de discutir elementos de uma atividade acadêmica de formação humana cuja ação principal é o exercício de pensar acerca da diferença, tendo como foco a clarificaçáo de noçóes e conceitos, se pauta na relevante distinção entre pensar e conhecer. Supomos que poucos duvidam da necessidade de conhecimento na formação de professores. Mas, face ao contexto sociopolítico e cultural que vivemos hoje, parece-nos crucial a necessidade de pensar além dos limites do conhecimento. Nas palavras de Arendt (1993, p. 149): “[...] se a habilidade para distinguir o certo e o errado tem alguma coisa a ver com a habilidade de pensar, então temos que ser capazes de exigir seu exercício por parte de toda pessoa sã.” Neste sentido, propomos neste artigo nos deter no exame dos conceitos de igualdade, e igualdade de oportunidades e ação afirmativa, com o intuito de explicitar esse exercício de pensamento.

\section{Da diferença, da igualdade e dos direitos humanos}

Caracterizada como um conceito relevante para a pós-modernidade, a diversidade cultural vem sendo intensamente discutida no âmbito educacional. Verifica-se que o pós-modernismo fornece fortes razóes para valorizar a diversidade, de modo a náo supor a homogeneidade quando ela não existe, e evitar práticas discursivas e não discursivas que excluam de forma implícita sujeitos que não participem dos modos dominantes de pensamentos (BURBULES; RICE, 1993).

Mas o que é a diversidade? O termo está relacionado com alteridade, diferença ou dessemelhança, pode indicar qualquer um desses ou todos juntos (ABBAGNANO, 2003, p. 291). Ao estudarmos a associação da diversidade com o conceito de diferença nas teorias sociais ou políticas, notamos que esse:

[...] nega a atribuição puramente externa e formal de pessoas a categorias de posiçóes sociológicas na estrutura social em virtude de algumas características que elas possuam, deve-se considerar também o processo ativo, subjetivo, de identificação com um 
grupo e tudo o que isso significa para o sujeito. (BURBULES; RICE, 1993, p. 183).

Um estudo relevante acerca dos conceitos de cultura, identidade e diferença é de autoria de Backes (2009), que investiga os significados destes termos nos trabalhos sobre afrobrasileiros e educação apresentados nas reuniōes da Anped no período de 2005 a 2008. Tendo como referências os estudos culturais, o autor observa que todos os trabalhos analisados apresentam um conceito de identidade e diferença que enfatiza seu caráter construído, relacional e histórico. Em nossa leitura do artigo, chama-nos a atenção que a vinculação dos conceitos de "identidade e diferença", fiel ao referencial teórico escolhido por Backes, não é explicitada, cabendo ao leitor reconhecer que, nesta perspectiva culturalista, “[...] a identidade é, na verdade relacional, e a diferença é estabelecida por uma marcação simbólica relativa a outras identidades", como distingue Kathryn Woodward (2004, p. 14; grifos da autora).

Muito se tem atribuído, em relação à noção de diferença nos dias atuais, aos estudos do filósofo Jacques Derrida (1930-2004), que, na tentativa de clarificar esse conceito, assim descreve:

[...] a différance não é uma distinção, uma essência ou uma oposiçáo, mas um movimento de espaçamento, um "devir-espaço" do tempo, um "devir-tempo" do espaço, uma referência à alteridade, a uma heterogeneidade que não é primordialmente oposicional. Daí uma certa inscrição do mesmo, que não é o idêntico, como différance. [...] Eu insisto, a différance não é uma oposição, tampouco uma oposição dialética: é uma reafirmação do mesmo, uma economia do mesmo em sua relaçáo com o outro. (DERRIDA; ROUDINESCO, 2004, p. 34).

Esta ênfase na "diferença” tem intrínseca relação com o princípio da igualdade que, segundo Rawls (1993), está constituído na "personalidade moral”, ou seja, ela é a base do princípio de que todos os seres humanos são iguais. No entanto, Singer (1994) critica o que, fundamentado nesta premissa, tem justificado que a igualdade de oportunidades seja o máximo da igualdade. É deste espaçamento entre esses dois filósofos que o presente 
trabalho buscará elucidar os aspectos relacionados ao princípio de igualdade e às oportunidades iguais, e suas implicações no contexto educacional.

Para exemplificar essa elucidação, faremos aqui o exercício de domínio conceitual recomendado para a implementação da Lei no 11.645 referente ao Plano Nacional de Implementação de Diretrizes Curriculares Nacionais para a Educação Étnico-raciais e para o Ensino de História e Cultura AfroBrasileira e Africana (PERNAMBUCO, 2008, p. 21).

A Lei no 10.639, de 9 de janeiro de 2003 (BRASIL, 2003), sancionada pelo Presidente da República, dispóe que:

Art. 26-A. Nos estabelecimentos de ensino fundamental e médio, oficiais e particulares, tornase obrigatório o ensino sobre História e Cultura Afro-Brasileira.

$\$ 1$ ㅇ O conteúdo programático a que se refere o caput deste artigo incluirá o estudo da História da África e dos Africanos, a luta dos negros no Brasil, a cultura negra brasileira e o negro na formação da sociedade nacional, resgatando a contribuiçáo do povo negro nas áreas social, econômica e política pertinentes à História do Brasil.

$\$ 2^{\circ}$ Os conteúdos referentes à História e Cultura Afro-Brasileira serão ministrados no âmbito de todo o currículo escolar, em especial nas áreas de Educação Artística e de Literatura e História Brasileiras.

Art. 79-B. O calendário escolar incluirá o dia 20 de novembro como Dia Nacional da Consciência Negra.

Art. 2o Esta Lei entra em vigor na data de sua publicação.

Uma das premissas dessa lei está em explicitar o papel do Estado Brasileiro de promover políticas de reparação direcionadas à educação da população afrodescendente, com vistas a garantir direitos iguais tais como indica a Constituição Federal em seu Artigo 205. Mencionamos a reflexão proposta por Souza (2009), que intenciona contribuir para o debate acerca das providências curriculares sugeridas pela lei aqui em pauta. Ao analisar o parecer da Lei no 10.639/2003, a autora destaca 
em suas diretrizes três princípios que orientam as açóes dos sistemas de ensino e dos professores:

- consciência política e história da diversidade;

- fortalecimento das identidades e de direitos; e

- ações afirmativas de combate ao racismo e discriminação.

Ao propor trabalhar os conceitos de preconceito e discriminação, ela segue a sugestão do parecer e enfatiza: “[...] eliminar conceitos, ideias e comportamentos, significa construir outros conceitos, outras ideias e outros comportamentos" (SOUZA, 2009, p. 4).

Inspirados nestas ações, atentamos para uma breve apresentação acerca dos direitos humanos e sua vinculação com o princípio de igualdade.

$\mathrm{O}$ valor da pessoa humana, caracterizado como um fundamento dos direitos humanos, é uma conquista histórico-axiológica. Historicamente, este valor se apresenta na tradição ocidental, inicialmente na Bíblia, no Velho Testamento, seguida do Talmud. Os estoicos buscam uma nova dignidade dos indivíduos na conversão de súdito das grandes monarquias. $\mathrm{O}$ cristianismo busca resgatar a ideia de que cada pessoa humana tem um valor absoluto no plano espiritual. A Reforma vai provocar a ruptura da unidade religiosa, derivando o primeiro direito individual reivindicado, a saber, a liberdade de opção religiosa. A proclamação dos direitos do homem aparece quando a fonte da lei deixa de ser o comando de Deus ou os costumes e passa a ser o homem. Atualmente, o reconhecimento do valor da pessoa humana como "valor-fonte" de todos os valores sociais vê-se ameaçado em uma civilização procriadora de incertezas, que, através de suas insistentes situaçóes socioeconômicas, éticas e políticas, tem colaborado para tornar os homens supérfluos e, consequentemente, sem lugar no mundo (LAFER, 1991).

$\mathrm{Na}$ perspectiva da filósofa Hannah Arendt (2000, p. 335):

[...] igualdade, em contraste com tudo o que se relaciona com a mera existência não nos é dada, mas resulta da organização humana, porquanto é orientada pelo princípio da justiça. Não nascemos iguais; tornamo-nos iguais como membros de um grupo por força da nossa decisão 
de nos garantirmos direitos reciprocamente iguais.

O exemplo da implementação da Lei 10.639 explicita a determinação do grupo de pessoas afrobrasileiras de garantir o direito de conhecer, pensar e compreender sua história e cultura. Deste modo, a igualdade:

[...] náo é um dado, [...] nem resulta de um absoluto transcendente externo à comunidade política. Ela é um construído, elaborado convencionalmente pela ação conjunta. Daí a indissolubilidade da relação entre o direito individual do cidadão de autodeterminar-se politicamente, em conjunto com seus concidadáos, através do exercício de seus direitos políticos, e o direito da comunidade de autodeterminar-se, construindo convencionalmente a igualdade. (LAFER, 1991, p. 150).

Um dos problemas que se verifica nessa construção da igualdade é que nem sempre a compreensão do conceito de igualdade abarca todas as pessoas. Neste sentido, alterca Arendt (2000, p. 335),

[...] o cenário obscuro do que é simplesmente dado, o pano de fundo constituído por nossa natureza imutável, adentra a cena política como elemento alheio que, em sua diferença demasiado óbvia, nos lembra as limitaçóes da atividade humana - que são exatamente as mesmas limitaçóes da igualdade humana. A razão pela qual comunidades políticas altamente desenvolvidas, como as antigas cidades-Estados ou os modernos Estados-nações, tão frequentemente insistem na homogeneidade é que esperam eliminar, tanto quanto possível, essas distinçóes e diferenciaçóes naturais e onipresentes que, por si mesmas, despertam silencioso ódio, desconfiança e discriminação, porque mostram com impertinente clareza aquelas esferas onde o homem não pode atuar e mudar à vontade, isto é, os limites do artifício humano. 
Ao examinarmos mais meticulosamente a noção de diferença, notamos que a autora revela a percepção do "estranho" como um símbolo assustador pelo fato da diferença em si, da individualidade em si, e evoca essa esfera na qual o homem náo pode atuar nem mudar e na qual tem, portanto, uma definida tendência a destruir. Exemplificamos que, se uma pessoa afrodescendente numa comunidade branca é considerada nada mais do que um negro, perde, juntamente com o seu direito à igualdade, aquela liberdade de ação especificamente humana. De semelhante modo sucede aos que perderam todas as qualidades políticas distintas e se tornaram seres humanos e nada mais. Por conseguinte, o pensamento arendtiano sentencia:

[...] dúvida, onde quer que a vida pública e a sua lei da igualdade se manifeste completamente, ou onde quer que uma civilização consiga eliminar ou reduzir ao mínimo o escuro pano de fundo das diferenças, o seu fim será a completa petrificação; será punida, por assim dizer, por haver esquecido que o homem é apenas o senhor, e não o criador do mundo. (ARENDT, 2000, p. 335).

Observamos que Hannah Arendt fundamenta o seu ponto de vista sobre os direitos humanos como invenção que exige a cidadania através de uma distinção ontológica que diferencia a esfera do privado da esfera do público. Para esta autora, a condição básica da ação e do discurso, em contraste com o labor e o trabalho, é o mundo comum da pluralidade humana. Esta tem uma característica ontológica dupla: a igualdade e a diferença. Se os homens não fossem iguais, não poderiam se entender. Por outro lado, se não fossem diferentes, não precisariam da palavra nem da ação para se fazerem entender. Ruídos seriam suficientes para a comunicaçáo de necessidades idênticas e imediatas. É com base nesta dupla característica da pluralidade humana que a filósofa insere a diferença na esfera do privado e a igualdade na esfera do público (LAFER, 1991, p. 151, grifos do autor). Deste modo, ao estudarmos os conceitos diferença, igualdade e direitos humanos, tendo como exemplo as leis 10.639 e 11.645 e no compasso da filosofia de Hannah Arendt, percebe-se com mais nitidez sua magnitude para a experiência do pensamento de professores em formação e desejável reverberação em suas atitudes e práticas pedagógicas. 


\section{Igualdade: um princípio da justiça}

Quando observamos os direitos de um indivíduo, estamos, consequentemente, nos pautando nos princípios de justiça. Por exemplo, o Art. $3^{\circ}$. da Constituição apregoa como um dos objetivos fundamentais da República Federativa do Brasil construir uma sociedade livre, justa e solidária (BRASIL, 1988, p. 3). Apresentando a justiça como a virtude primeira das instituiçóes sociais, John Rawls (1993) afirma que, numa sociedade justa, a igualdade de liberdades e direitos entre os cidadãos é considerada definitiva. Esta afirmação enfatiza o papel que os princípios de justiça desempenham dentro de um contexto social. O autor explica que esses "[...] fornecem um critério para a atribuição de direitos e deveres nas instituiçóes básicas da sociedade e definem a distribuição adequada dos encargos e benefícios da cooperação social" (RAWLS, 1993, p. 33). A teoria de justiça proposta por esse filósofo parte de uma concepçáo contratualista e tem como tema a justiça social, apresentando que o objeto primário da justiça é a estrutura básica da sociedade, ou seja, o modo pelo qual as principais instituiçóes sociais distribuem os direitos e deveres fundamentais, e determinam a divisão dos benefícios da cooperação em sociedade.

Podemos apreender uma ideia à qual a justiça se refere, que é dar aos outros o que lhes é devido, o que merecem ou deveriam ter. Isso pressupóe fazer um julgamento a respeito da pessoa humana, de seu comportamento e das próprias normas que regulam o próprio comportamento (WREN, 1979, p. 43, ABBAGNANO, 2003, p. 593). Tal tarefa exige cálculo e reflexão. Portanto, fazer justiça requer a faculdade da razão.

Na designaçâo de sua teoria da justiça como equidade, Rawls (1993, p. 34) afirma que os indivíduos livres e racionais aceitam os princípios da justiça colocados numa situaçáo inicial de igualdade. Estes princípios regulamentam os acordos, especificam as formas da cooperação social que podem ser introduzidas, bem como as formas de governo que podem ser estabelecidas. Deste modo, explicita o autor que:

[...] os princípios da justiça são escolhidos a coberto de um véu de ignorância. Assim se garante que ninguém é beneficiado ou prejudicado na escolha daqueles princípios pelos resultados do acaso natural ou pela contingência das circunstâncias sociais. Uma vez que 
todos os participantes estão em situação semelhante e que ninguém está em posição de designar princípios que beneficiem a sua situação particular, os princípios da justiça são o resultado de um acordo ou negociação equitativa. (RAWLS, 1993, p. 34).

Essa perspectiva da justiça como imparcialidade apresenta como aspecto favorável a convicção básica de se elaborar princípios de justiça solidamente fundados na razão. Por outro lado, sua fragilidade está em admitir as pessoas em sua posição original, ou seja, como indivíduos separados, autossuficientes, em nada afetados pelos que os cercam. Como sinaliza criticamente Wren (1979, p. 53): “[...] na realidade, porém, não há ser humano capaz de existir desta maneira isolada. Só nos conhecemos a nós mesmos em função de relaçôes com os outros". A relevância de estudar a teoria de John Rawls se sustenta na referência que esta é para o sistema jurídico contemporâneo. Se queremos criar novos conceitos, parece-nos necessário sabermos como desconstruir alguns. Para isso, é necessário reconhecer a qualidade dos fios que os tecem.

Escolhemos agora nos enveredar pelo conceito de oportunidades iguais na educação, tendo como fio condutor o estudo de dois princípios relativos às instituiçóes, que são explicitados na teoria de justiça de Rawls (1993, p. 68), na qual o primeiro princípio prescreve que:

[...] cada pessoa deve ter um direito igual ao mais amplo sistema total de liberdades para todos. $\mathrm{O}$ segundo princípio: as desigualdades econômicas e sociais devem ser distribuídas por forma a que simultaneamente: a) redundem nos maiores benefícios para os menos beneficiados, de uma forma que seja compatível com o princípio da poupança justa, e b) sejam a consequência do exercício de cargos e funçôes abertos a todos em circunstâncias de igualdade equitativa de oportunidades.

Considerando o sistema de liberdade natural, e dada a ambiguidade das expressóes "em benefício de todos" e " funçóes às quais todos têm acesso", o autor interpreta o segundo princípio a partir de dois significados independentes entre si: o princípio da eficiência e o princípio da diferença. 
Considera, assim, o sistema de liberdade natural, a igualdade em sentido liberal e a igualdade democrática. Nas palavras do filósofo:

[...] a interpretação liberal dos dois princípios visa a mitigar a influência das contingências sociais e da fortuna natural na distribuiçáo. Para atingir este objetivo é necessário impor condiçôes estruturais básicas suplementares ao sistema inicial. $\mathrm{O}$ mercado livre deve ser visto no quadro de uma estrutura de instituiçóes políticas e jurídicas que regule as tendências globais dos fatos econômicos e salvaguarde as condiçóes sociais necessárias para a igualdade equitativa de oportunidades. Os elementos desta estrutura são conhecidos, embora possa valer a pena recordar como é importante que se evite uma acumulação excessiva da propriedade e da riqueza e que se mantenha a igualdade de oportunidades de educação para todos. As possibilidades de adquirir conhecimentos de natureza cultural e qualificaçóes não devem depender da posiçáo de classe, pelo que o sistema escolar, quer seja público ou privado, deve ser traçado para eliminar as barreiras de classe. (RAWLS, 1993, p. 76).

Após as interpretaçóes pautadas no sistema de liberdade natural e da igualdade em sentido liberal, segue-se o da igualdade democrática, cuja preferência é assumida pelo autor ao escrever que essa última:

[...] é obtida pela combinação do princípio da igualdade equitativa de oportunidades com o princípio da diferença. Este princípio elimina a indeterminaçáo do princípio da eficiência ao isolar uma posição particular a partir da qual as desigualdades econômicas e sociais da estrutura básica devem ser julgadas. Partindo da estrutura institucional exigida pela igual liberdade e 
pela igualdade equitativa de oportunidades, as expectativas mais elevadas dos sujeitos que estão melhor situados são justas se e apenas se funcionarem como parte de um sistema que melhore as expectativas dos membros menos beneficiados da sociedade. A ideia intuitiva é a de que a ordem social não deve permitir e garantir as perspectivas dos que estão materialmente melhor a não ser que, ao fazê-lo, beneficie os que são menos afortunados. (RAWLS, 1993, p. 78).

Em um artigo intitulado "Reflexóes sobre Little Rock", Hannah Arendt (2004) tem como ponto de partida uma fotografia nos jornais da época que mostrava uma menina negra saindo de uma escola recém-integrada no caminho de casa, perseguida por uma turba de crianças brancas, protegida por um amigo branco de seu pai; na descrição, a filósofa ressalta que a face da menina dava testemunho eloquente do fato óbvio de que ela não estava precisamente feliz. Na tentativa de se colocar no lugar do outro, ela escreve: “[...] sentiria que a própria tentativa de começar a dessegregação na educação e nas escolas não tinha apenas deslocado, e muito injustamente, a carga da responsabilidade dos ombros dos adultos para os das crianças" (ARENDT, 2004, p. 262). E se posiciona: “[...] a questão real é a igualdade perante as leis do país, e a igualdade é violada pelas leis da segregação, isto é, por leis que impóem a segregação, e não por costumes sociais e maneiras de educar as crianças" (ARENDT, 2004, p. 262). Mas adiante ela menciona que, se a questão fosse apenas de educação igualmente boa, um esforço para conceder oportunidades iguais, ela poderia se ver forçada a tomar atitudes para assegurar uma vida decente, mas, ainda que a vida fosse desagradável, ela podia conservar a integridade pessoal, por agir por coação, por necessidade vital, e não meramente por razões sociais (ARENDT, 2004). Se a implementação de uma lei considera ou não o igual interesse dos envolvidos, de uma forma ou de outra essa lei, nos parece, merece ser examinada.

\section{Igualdade de consideração}

Na busca dos fundamentos éticos do princípio de igualdade, o filósofo Peter Singer parte de um ponto de vista utilitarista diferente de John de 
Rawls, que pauta sua teoria na perspectiva contratualista, como foi visto anteriormente. Peter Singer inicia sua discussão questionando qual é a base da igualdade, ou seja, o que significa dizer que todos os seres humanos são iguais. Os racistas, sexistas e outros adversários da igualdade têm mostrado frequentemente que, qualquer que seja a forma de comprovação que busquemos, a verdade pura e simples é que os seres humanos não são todos iguais. Esta constatação nos favorece também para dizer que o fato é que os seres humanos diferem entre si e que as diferenças remetem a tantas características, que a busca de uma base verdadeira sobre a qual se pudesse construir o princípio da igualdade parece inatingível (SINGER, 1994).

A seguir, vamos explicitar como Peter Singer critica algumas sugestóes sobre a igualdade, indicadas por John Rawls na obra Uma teoria da Justiça, mencionada por nós nos parágrafos anteriores. Primeiramente, Rawls sugere que a igualdade pode se fundamentar nas características naturais dos seres humanos, desde que selecionemos sua propriedade de âmbito. ${ }^{1} \mathrm{Em}$ segundo lugar, Rawls sugere que a propriedade de "personalidade moral" é uma propriedade que, virtualmente, todos os seres humanos possuem, e todos os que a possuem possuem-na igualmente. Esclarece assim o filósofo:

[...] por "personalidade moral" Rawls não quer dizer" personalidade moralmente boa", ele usa o termo "moral" em contraste com "amoral". Uma pessoa moral, diz Rawls, deve possuir um senso de justiça. Em termos mais amplos, poderíamos dizer que ser uma pessoa moral implica ser o tipo de pessoa à qual se pode fazer uma invocação moral com alguma perspectiva de que a invocação vá ser levada em conta. (SINGER, 1994, p. 27).

Continuando, o autor explicita duas objeçóes referentes ao uso da personalidade moral como base da igualdade. A primeira, ele problematiza dizendo que ter uma personalidade moral é uma questão de grau; exemplificando, algumas pessoas são extremamente sensíveis a questóes de justiça e ética; outras, por uma multiplicidade de razóes, têm somente uma consciência limitada de tais princípios. A sugestão de que ser uma pessoa moral é o mínimo necessário para se situar na esfera do princípio de igualdade ainda deixa em aberto a questão de saber onde se deve traçar a linha que delimite esse mínimo. A segunda objeção se pauta na negação de que todos 
os seres humanos são pessoas morais, mesmo no sentido mais ínfimo. Por exemplo, ao lado de indivíduos com problemas mentais, os bebês carecem do necessário senso de justiça. Pergunta o autor: "Diremos, então, que todos os seres humanos são iguais com exceção dos muitos jovens ou dos mentalmente incapacitados? Não é isso, por certo, o que em geral se entende por princípio de igualdade" (SINGER, 1994, p. 28). Deste modo, o autor conclui sua crítica afirmando que a posse de uma "personalidade moral" náo oferece uma base satisfatória para o princípio de que todos os seres humanos são iguais. E duvida que qualquer característica natural, seja ela uma "propriedade de âmbito" ou não, possa desempenhar essa função, pois duvida também que exista qualquer propriedade moralmente significativa que todos os seres humanos possuam por igual.

Qual seria, então, outra possibilidade para a crença de que há uma base factual para um princípio de igualdade que proíba o racismo e o sexismo? Uma resposta poderia estar em admitirmos que os seres humanos diferem como indivíduos e, ainda assim, insistir na afirmação de que não existem diferenças moralmente significativa. No entanto, para Singer não há nenhuma razão logicamente imperiosa que nos force a pressupor que uma diferença de capacidade entre duas pessoas justifique uma diferença na consideração que atribuímos aos seus interesses. Pois a igualdade é um princípio ético básico. Ao fazer um juízo ético, expóe o autor:

[...] devo ir além de um ponto de vista pessoal ou grupal, e levar em consideração os interesses de todos os que forem por ele afetados. Isso significa que refletimos sobre os interesses, considerados simplesmente como interesses, e não como meus interesses, ou como interesses dos australianos ou de pessoas de descendência europeia. Isso nos proporciona um princípio básico de igualdade: o princípio da igual consideração dos interesses. A essência do princípio da igual consideração significa que, em nossas deliberaçôes morais, atribuímos o mesmo peso aos interesses semelhantes de todos os que são atingidos por nossos atos. (SINGER, 1994, p. 30).

Ao observamos em nosso país as grandes diferenças de renda e status social, estas costumam ser vistas com naturalidade. É comum ouvir 
estudantes comentarem que, para estudar em uma universidade pública, a pessoa tem que estudar, a vaga está disponível para aqueles que se esforçaram para ocupá-la. Deste modo,

[...] a vida é uma espécie de corrida na qual é justo que os vencedores levem os prêmios, desde que todos tenham o mesmo ponto de partida. $O$ ponto de partida igual representa igualdade de oportunidades, e isto, dizem alguns, é o máximo a que pode chegar a igualdade, mas [...] a igualdade de oportunidades não é um ideal atraente. Recompensa os que têm sorte, os que herdam aquelas aptidóes que lhes permitem desenvolver carreiras interessantes e lucrativas e castiga o desventurado cujos genes fazem com que lhe seja muito difícil alcançar o mesmo sucesso (SINGER, 1994, p. 48-49).

A crítica que Peter Singer faz ao princípio de igualdade de oportunidade mostra que, se não tivermos parâmetros éticos que nos ajudem a esclarecer os critérios a adotar, podemos ser injustos. A proposição do princípio da igual consideração de interesses possibilita ir além do princípio da igualdade de oportunidades, pois, para que ela ocorra, é exigida de nós a certeza de que, por exemplo, as escolas ofereçam a todos as mesmas vantagens. Acreditamos que, no atual momento, somente uma atitude ética, expressada no princípio de igual consideração de interesses, poderia oportunizar a efetivação da democratização da educação. Neste sentido, a ação afirmativa pode ser uma alternativa.

\section{A ação afirmativa}

$\mathrm{Na}$ trilha de Peter Singer, constatamos que a transição para uma sociedade mais igualitária, na qual as diferenças fossem mitigadas, é tão eticamente desejável quanto de difícil concretização na prática. Considerando a impossibilidade de instituir uma igualdade geral, poderíamos ao menos tentar garantir que, onde existem relevantes diferenças de renda, status e poder, as mulheres e as minorias étnicas não fiquem na extremidade 
mais desfavorecida, em números desproporcionais aos seus números na comunidade como um todo. Expóe o filósofo que

[...] as desigualdades entre membros do mesmo grupo étnico podem não ser mais justificáveis do que as que se verificam entre grupos étnicos, ou entre homens e mulheres; mas, quando essas desigualdades coincidem com uma diferença óbvia entre pessoas, como as diferenças entre afro-americanos e americanos de descendência europeia, ou entre homens e mulheres, elas contribuem mais para produzir uma sociedade dividida, com um sentimento geral de superioridade, de um lado, e um sentimento geral de inferioridade, de outro. Portanto, a desigualdade racial e sexual pode ter um efeito mais separatista do que outras formas de desigualdade. Também pode contribuir para criar um sentimento de desesperança entre os membros do grupo inferior, uma vez que o seu sexo ou a sua raça não é produto de suas açóes, nada havendo que possam fazer para mudar tal estado de coisas. (SINGER, 1994, p. 54).

O modo que o autor aponta para exceder tais obstáculos consiste em extrapolar a igualdade de oportunidades e dar um tratamento preferencial a membros dos grupos menos favorecidos. É a isto que se dá o nome de ação afirmativa. Talvez aí esteja uma esperança de reduzir as desigualdades permanentes, ainda que pareça transgredir o próprio princípio de igualdade (SINGER, 1994, p. 54).

A ação afirmativa é um programa criado para corrigir os efeitos da discriminaçáo racial e sexual em empresa, escolas, etc., e se caracteriza como uma medida redistributiva. Emergiu na década de 1960, nos Estados Unidos da América, no auge da batalha entre os que lutavam pela igualdade racial. A educação é um campo de importância específica, uma vez que influi significativamente sobre as perspectivas de conseguir bons salários, empregos satisfatórios, poder e status na comunidade (WEST, 1994; SINGER, 1994). 
Em uma nota conclusiva, Singer inclui em sua discussão sobre a igualdade as pessoas com necessidades especiais. Ele discute que muitos dos argumentos favoráveis à ação afirmativa, no caso dos que são prejudicados devido à raça ou ao sexo, se aplicam ainda mais fortemente às pessoas categorizadas como portadores de deficiência. A mera igualdade de oportunidade não será suficiente em situaçóes nas quais uma ausência de um sentido ou de uma parte do corpo impeça que alguém se torne membro igual da comunidade. E propóe atribuirmos igual consideração aos interesses das pessoas com necessidades especiais, e, através de um processo de empatia, imaginando-nos em sua situação, podemos, em princípio, chegar à resposta certa; mas não será fácil determinar exatamente qual, em cada situação específica, deva ser a resposta (SINGER, 1994, p. 62-63).

A proposição da aplicação da ação afirmativa aos membros de grupos minoritários nos favorece extrapolar o princípio de igualdade de oportunidades. Isso nos possibilita também ampliar a nossa visão sobre o direito e o respeito à diferença, e acolhermos a singularidade humana, assumirmos uma atitude ética. No entanto, a ética exige que extrapolemos o "eu" e o "você", e cheguemos à lei universal, ao juízo universalizável, ao ponto de vista do espectador imparcial, ao observador ideal. Tal como Arendt (2000a, p. 82) nos revela ao examinar que em sua

[...] incessante conversa os gregos descobriram que o mundo que temos em comum é usualmente considerado sob um infinito número de ângulos, aos quais correspondem os mais diversos pontos de vista. [...] Os gregos aprenderam a compreender - não a compreender um ao outro como pessoas individuais, mas a olhar sobre o mesmo mundo do ponto de vista do outro, a ver o mesmo em aspectos bem diferentes e frequentemente opostos.

Partindo dessa conversação, podemos ponderar, finalmente, sobre a inflexão do papel que o pensamento racional e o argumento desempenham no estabelecimento de uma atitude ética, tendo como referência a formação de professores. Se no início deste trabalho denunciamos o impacto dos juízo perceptivo no encontro com o outro, chegamos agora ao ponto de admitirmos que os juízos éticos devem ser formados a partir de um ponto de vista universal. 
Com isso estamos, nas palavras de Singer (1994, p. 20): “[...] aceitando que os meus próprios interesses, simplesmente por serem meus interesses, não podem contar mais que os interesses de uma outra pessoa". O exame meticuloso da noçáo da diferença aqui aplicado buscou explicitar como as palavras que usamos não são neutras ou despojadas de sentido. Percebemos, assim, como a diferença está implicada com a igualdade de direitos. Porém, reconhecermos interesses comuns pode ser uma tarefa laboriosa. Conscientes de que o trabalho não se encerra neste texto, talvez no próximo passo desse nosso andar incoativo devemos voltar o nosso olhar, afinar a nossa escuta para as nossas crianças e verificar, por exemplo, o quanto a implementaçáo da Lei 10.639 tem ido ao encontro dos seus interesses. Com certeza, os fios soltos de suas narrativas e experiências existenciais ajudarão a solidificar a experiência de pensamento de qualquer pessoa que queira compreender o sentido de ser-no-mundo. Já que desejamos criar muitas moradas por aqui, que essas possam ser acolhedoras.

\section{Nota}

1 Singer (1994, p. 27) exemplifica: "Vamos supor que tracemos um círculo num pedaço de papel. Todos os pontos no interior do círculo - é esse o âmbito - têm a propriedade de estar dentro do círculo, têm igualmente essa propriedade. Alguns pontos podem estar mais próximos do centro, outros mais próximos da periferia, mas todos são, igualmente, pontos no interior de um círculo".

\section{REFERÊNCIAS}

ABBAGNANO, Nicola. Dicionário de Filosofia. São Paulo: Martins Fontes, 2003.

ARENDT, Hannah. A dignidade da politica. Rio de Janeiro: RelumeDumará,1993. . Entre o passado e o futuro. Rio de Janeiro: Perspectiva, 2000a. . Homens em tempos sombrios. São Paulo: Companhia das Letras, 1999. 
ARENDT, Hannah. Origens do totalitarismo: anti-semitismo, imperialismo, totalitarismo. São Paulo: Companhia das Letras, 2000b. . Reflexôes sobre Little Rock. In: H. Arendt. Responsabilidade e julgamento. São Paulo: Companhia das Letras, 2004.

BACKES, José Licínio. Os significados dos conceitos de cultura, identidade e diferença nos trabalhos sobre afrobrasileiros e educação, e suas implicaçôes epistemológicas. In: REUNIÃO ANUAL DA ASSOCIAÇĀO NACIONAL DE PÓS-GRADUAÇÃO E PESQUISA EM EDUCAÇÃO (ANPED), 32, 2009, Caxambu. Anais eletrônicos... Caxambu: ANPED, 2009. GT 21 - 5264 - Educação e Relaçôes ÉtnicoRaciais. Disponível em: <http://www.anped.org.br/reunioes/32ra/ arquivos/trabalhos/GT21-5264--Int.pdf>. Acesso em: 27 out. 2009. BRASIL. [Constituição (1988)]. Constituição da Republica Federativa do Brasil: promulgada em 5 de outubro de 1988. Brasília: Centro Gráfico do Senado Federal, 1988.

BRASIL. Presidência da República. Casa Civil. Lei no 10.639, de 9 de janeiro de 2003. Altera a Lei no 9.394 , de 20 de dezembro de 1996, que estabelece as diretrizes e bases da educaçáo nacional, para incluir no currículo oficial da Rede de Ensino a obrigatoriedade da temática "História e Cultura Afro-Brasileira", e dá outras providências. In: BRASIL. Presidência da República Federativa do Brasil. Legislação: leis: leis ordinárias de 2003. Brasília, 2003. Disponível em: <http://www.planalto.gov.br/ ccivil_03/Leis/2003/L10.639.htm>. Acesso em 27 out. 2009.

BURBULES, Nicholas; RICE, Suzanne. Diálogo entre as diferenças: continuando a conversação. In: SILVA, Tomaz (Org.). Teoria educacional crítica em tempos pós-modernos. Porto Alegre: Artes Médicas, 1993.

DERRIDA, Jaques; ROUDINESCO, Elisabeth. De que amanhã... Diálogo. Rio de Janeiro: Jorge Zahar, 2004.

GOFFMAN, Erving. Estigma: notas sobre a manipulação da identidade deteriorada. 4. ed. Rio de Janeiro: Guanabara, 1988.

HUSSERL, Edmund. Investigaçôes lógicas: sexta investigação. São Paulo: Abril, 1980. (Os Pensadores). 
ITANI, Alice. Vivendo o preconceito em sala de aula. In: J. G. Aquino. Diferenças e Preconceito na escola: alternativas teóricas e práticas. São Paulo: Summus, 1998.

LAFER, Celso. A reconstrução dos direitos humanos: um diálogo com o pensamento de Hannah Arendt. São Paulo: Companhia das Letras, 1991.

LUNARDI, Geovana Mendonça. As práticas curriculares de sala de aula e a constituição das diferenças dos alunos no processo de ensino e aprendizagem. In: REUNIÃO ANUAL DA ASSOCIAÇÃO NACIONAL DE PÓS-GRADUAÇÃO E PESQUISA EM EDUCAÇÃO (ANPED), 28, 2005, Caxambu. Anais eletrônicos... Caxambu: Anped, 2005. Trabalhos e Pôsteres: GT 15 - Educação Especial. Disponível em: <http://www.anped.org.br/reunioes/28/inicio. htm>. Acesso em: 26 mar. 2009.

MORAN, Dermot. Introduction to phenomenology. London: Routledge, 2000.

PERNAMBUCO. Ministério Público. Plano Nacional de Implementação Diretrizes Curriculares Nacionais para a Educação Étnico-Raciais e para o Ensino de História e Cultura Afro-Brasileira e Africana. Pernambuco, 2008. Disponível em: < http://www.mp.pe.gov.br/uploads/.../ planonacional_10.6391.pdf $>$. Acesso em: 29 mar. 2009.

RAWLS, John. Uma teoria da justiça. Lisboa: Presença, 1993.

REGO, Teresa Cristina R. Educação, cultura e desenvolvimento: o que pensam os professores sobre as diferenças individuais. In: AQUINO, Julio Groppa (Org.). Diferenças e preconceito na escola: alternativas teóricas e práticas. São Paulo: Summus,1998. p. 49-71.

SINGER, Peter. Ética prática. São Paulo: Martins Fontes, 1994.

SOUZA, Maria Elena Viana. Diálogos possíveis entre concepções de currículo e a Lei 10.639/03. In: REUNIÃO ANUAL DA ASSOCIAÇÃO NACIONAL DE PÓS-GRADUAÇÃO E PESQUISA EM EDUCAÇÃO (ANPED), 32, 2009, Caxambu. Anais eletrônicos... Caxambu: ANPED, 2009. GT 21 - 5547 - Educação e Relaçôes ÉtnicoRaciais. Disponível em: <http://www.anped.org.br/reunioes/32ra/ arquivos/trabalhos/GT21-5547--Int.pdf> . Acesso 27 out. 2009. 
TAJFEL, Henri. Grupos humanos e categorias sociais. Lisboa: Livros Horizonte, 1982. v. 1a e 2b.

WEST, Cornel West. Questão de raça. São Paulo: Companhia das Letras, 1994.

WREN, Brian. Educação para a justiça. São Paulo: Loyola, 1979.

WOODWARD, Kathryn. Identidade e diferença: uma introdução teórica e conceitual. In: T. T. da Silva (Org.). 3. ed. Identidade e diferença. Petrópolis: Vozes, 2004. p. 7-72 
Between thinking and knowing: a place for difference in teacher education

\section{Abstract}

In an attempt to distinguish thinking and knowing, this article presents an exercise in thinking as an academic activity in teacher education. The text is based on a critical examination of concepts related to equal access to education, knowledge, stigma, difference, human rights, equality and equal opportunities and affirmative action in dialog with some contemporary philosophers such as Hannah Arendt, Jacques Derrida, John Rawls and Peter Singer. It follows a path that begins with perceptive judgment and extends to ethical judgment, which it attributes to giving equal consideration to interests.

Key words: Equality in education. Teacher - education.

\section{Ida Mara Freire}

Rua Bosque dos Eucaliptos, 167

Telefone: 3721-9245

CEP: 88 063-440 - Florianópolis-SC

E-mail: idamara@ced.ufsc.br

\section{Entre el pensar y el conocer: un lugar para la diferencia en la formación de profesores}

\section{Resumen}

El presente artículo presenta, procurando distinguir entre pensar y conocer, realizar un ejercicio de pensamiento como posibilidad de una actividad académica en la formación de docentes. El texto apunta un examen crítico de algunas nociones que giran alrededor de la igualdad de derecho a la educación, como por ejemplo, estigma, derechos humanos, igualdad e igualdad de oportunidades y acción afirmativa. Para tal, o texto se apoya en algunos filósofos contemporáneos: Hannah Arendt, Jacques Derrida, John Rawls e Peter Singer. Realizamos un camino que parte del juicio perceptivo llegando al juicio ético, que atribuye la misma consideración de intereses.

Palabras clave: Igualdad en la educación. Docentes. Formación.

Recebido em: 28/2/2010 Aprovado em: 31/5/2010 